\title{
In Vivo Anticancer Activity of a Rhenium(I) Tricarbonyl Complex
}

\author{
Chilaluck C. Konkankit, ${ }^{\dagger}$ A. Paden King, ${ }^{\dagger}$ Kevin M. Knopf, ${ }^{\dagger}$ Teresa L. Southard, ${ }^{\S}$ \\ and Justin J. Wilson*, ${ }^{\dagger}$ \\ ${ }^{\dagger}$ Department of Chemistry and Chemical Biology, Cornell University, Ithaca, New York 14853, United States \\ ${ }^{\S}$ Department of Biomedical Sciences, Cornell University, Ithaca, New York 14853, United States
}

\section{Supporting Information}

\begin{abstract}
The rhenium(I) complex fac- $\left[\operatorname{Re}(\mathrm{CO})_{3}\right.$ (2,9-dimethyl-1,10phenanthroline $\left.)\left(\mathrm{OH}_{2}\right)\right]^{+}(\mathbf{1})$ was previously shown to exhibit potent in vitro anticancer activity in a manner distinct from conventional platinum-based drugs (J. Am. Chem. Soc. 2017, 139, 14302-14314). In this study, we report further efforts to explore its aqueous speciation and antitumor activity. The cellular uptake of 1 was measured in A2780 and cisplatin-resistant A2780CP70 ovarian cancer cells by inductively coupled plasma mass spectrometry, revealing similar uptake efficiency in both cell lines. High accumulation in the mitochondria was observed, contradicting prior fluorescence microscopy studies. The luminescence of $\mathbf{1}$ is highly dependent on $\mathrm{pH}$ and coordination environment, making fluorescence microscopy somewhat unreliable for determining compound localization. The in vivo anticancer activity of $\mathbf{1}$ was evaluated in mice bearing patient-derived ovarian cancer tumor xenografts. These studies conclusively show that $\mathbf{1}$ is capable of inhibiting tumor growth, providing further credibility for the use of these compounds as anticancer agents.
\end{abstract}

KEYWORDS: Rhenium tricarbonyl, tumor growth inhibition, ovarian cancer, mice xenografts, metallodrug, histopathology

$\mathrm{D}$ espite their widespread use for cancer treatment, the platinum-based drugs cisplatin and carboplatin suffer from several key limitations. ${ }^{1}$ For example, these drugs induce toxic side effects and are susceptible to drug resistance. ${ }^{2}$ The success of the platinum-based drugs, however, has sparked interest in developing new drug candidates containing metal centers. Complexes of gold, ${ }^{3}$ titanium, ${ }^{4}$ and ruthenium ${ }^{5}$ have been shown to exhibit anticancer activity via novel mechanisms of action. The promise of these alternative metal complexes is exemplified by the current clinical trials of the gold drug candidate, auranofin, ${ }^{6}$ and the ruthenium drug candidates, NAMI-A, ${ }^{7}$ NKP-1339, ${ }^{8}$ and TLD-1433. ${ }^{9}$ Recently, efforts in this area have expanded to compounds of other third row transition metals, such as rhenium, osmium, and iridium. ${ }^{10-14}$ Rhenium complexes, in particular, are rapidly gaining interest as anticancer agents because of their high stability, structural diversity, and rich spectroscopic properties. ${ }^{15}$ Many reports have demonstrated their promising in vitro anticancer activity, but few studied the potential efficacy of these complexes in vivo. ${ }^{16-22}$ Among the potential rhenium anticancer agents, compounds containing the stable rhenium(I) tricarbonyl core have been extensively explored for both imaging and therapeutic applications. ${ }^{23,24}$ Our lab has investigated many rhenium tricarbonyl complexes for anticancer activity, ${ }^{25,26}$ efforts that have led us to identify compound $\mathbf{1}$ (Chart 1 ) as a drug candidate that is more potent than cisplatin in HeLa cells. $^{27}$ This complex induces cell death in a manner distinct from cisplatin, resulting in a lack of cross-resistance between
Chart 1. Structure of Compound 1, a Potent Rhenium-based Anticancer Agent

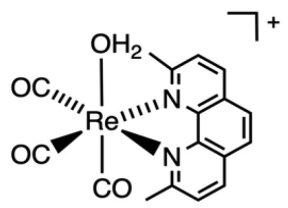

1

these compounds. Additional in vivo biodistribution and metabolite studies confirmed compound stability and suggested renal and hepatobiliary excretion. Having established compound $\mathbf{1}$ as a practical drug candidate, we sought to investigate its aqueous speciation, subcellular localization, and in vivo anticancer activity to further understand the therapeutic potential of this class of rhenium complexes.

In order to evaluate potential intracellular targets, we investigated the cellular uptake and subcellular localization of 1 in both wild-type (A2780) and cisplatin-resistant (A2780CP70) ovarian cancer cells using inductively coupled plasma mass spectrometry (ICP-MS) (Table 1). Upon incubation with $1(10 \mu \mathrm{M}, 24 \mathrm{~h})$, the total cellular uptake amounted to 0.18 and $0.20 \mathrm{ng}$ of rhenium per $\mu \mathrm{g}$ of protein in

Received: March 22, 2019

Accepted: April 16, 2019

Published: April 23, 2019 
Table 1. Cellular Fractionation Uptake Data for 1 Quantified Using ICP-MS ${ }^{a}$

$\begin{array}{lcc}\text { cell fraction } & \begin{array}{c}\text { Re content in A2780 cells } \\ (\mathrm{ng} / \mu \mathrm{g} \text { protein })\end{array} & \begin{array}{c}\text { Re content in A2780CP70 } \\ \text { cells }(\mathrm{ng} / \mu \mathrm{g} \text { protein })\end{array} \\ \text { whole cell } & 0.18 \pm 0.03 & 0.20 \pm 0.11 \\ \text { nuclei } & 0.21 \pm 0.03 & 0.20 \pm 0.17 \\ \text { mitochondria } & 1.49 \pm 0.12 & 2.31 \pm 1.76\end{array}$

${ }^{a_{T}}$ The errors represent the standard error from three independent experiments. Protein content was determined with bicinchoninic acid assays.

A2780 and A2780CP70 cells, respectively. Thus, compound 1 is taken up equally well in both of these cell lines. By contrast, cisplatin exhibits significantly diminished uptake in the A2780CP70 cells, a consequential feature of the cisplatinresistant phenotype of this cell line. ${ }^{28}$ The cellular components were further fractionated to separate the nuclei and mitochondria. Analysis of these fractions reveals that a small, but detectable, quantity of rhenium is found in the nuclei. By contrast, a significant amount of rhenium is observed in the mitochondria, suggesting that $\mathbf{1}$ preferentially localizes to this organelle. Although mitochondria are common targets for rhenium complexes, ${ }^{10,29}$ this result contradicts our previous study in which we probed the intracellular localization of 1 by confocal fluorescence microscopy. ${ }^{27}$ These microscopy data suggested that $\mathbf{1}$ induces cytoplasmic vacuolization and localizes primarily in the lysosomes. No significant luminescence signatures were detected in other organelles, including the nucleus and mitochondria, whereas the ICP-MS data indicates high levels of rhenium in the mitochondria. The inconsistency between the apparent mitochondrial uptake, determined by ICP-MS and microscopy, may arise from environmental sensitivity or luminescence speciation dependence of 1, rendering the detection capabilities of fluorescence microscopy for $\mathbf{1}$ unreliable. A similar discrepancy between ICP-MS and microscopy data has been observed for organometallic rhenium complexes conjugated to doxorubicin. $^{30,31}$ These reports noted that fluorescence microscopy failed to detect these compounds in the nucleus because their emission is quenched upon DNA intercalation. Similarly, the luminescence properties of $\mathbf{1}$ may be affected by its speciation. Another study reports on a luminescent heteronuclear manganese-rhenium complex in situ. ${ }^{32}$ Despite the fact that this compound exhibited high cellular uptake, no luminescence signatures were observed in living cells, further demonstrating how the speciation of rhenium complexes can greatly alter its photophysical properties.

Because the axial water ligand of $\mathbf{1}$ is susceptible to deprotonation, we hypothesized that its luminescence is affected by its protonation state. Thus, the fluorescence microscopy studies may reflect the observation of $\mathbf{1}$ only in its bright state. Therefore, we determined the $\mathrm{p} K_{\mathrm{a}}$ of the coordinated water by carrying out a UV-vis spectrophotometric titration (Figure S1a). ${ }^{33}$ The $\mathrm{p} K_{\mathrm{a}}$ value of the coordinated water of 1 was determined to be 8.3 (Figure $\mathrm{S} 1 \mathrm{~b})$. Notably, this value is higher than that of [Re$\left.(\mathrm{CO})_{3}\left(\mathrm{OH}_{2}\right)_{3}\right]^{+}$, which has a $\mathrm{pK}$ of 7. . $^{34}$ The higher $\mathrm{p} K_{\mathrm{a}}$ of 1 in comparison to $\left[\operatorname{Re}(\mathrm{CO})_{3}\left(\mathrm{OH}_{2}\right)_{3}\right]^{+}$may be due to the increased electron donation of the diimine ligand relative to the water ligands, which decreases the electron-withdrawing effects of the rhenium center. Based on its $\mathrm{p} K_{\mathrm{a}}$ of 8.3, compound $\mathbf{1}$ exists predominately as the aqua complex in neutral/acidic regions of intracellular compartments. Under basic conditions, such as in the mitochondrial matrix $(\mathrm{pH} \approx$ $8.0),{ }^{35}$ compound $\mathbf{1}$ will also exist in the hydroxo form. To assess the influence of the protonation state on luminescence intensity of 1 , we measured its emission spectrum at varying $\mathrm{pH}$ values (Figure S2). The luminescence intensity of 1 increases at lower $\mathrm{pHs}$. These data may explain our previous results in which fluorescence microscopy showed high luminescence intensity of $\mathbf{1}$ in the acidic lysosomes $(\mathrm{pH}<$ $5.0) .^{36}$ At highly basic $\mathrm{pH}$ values $(>10)$, the emission intensity of $\mathbf{1}$ is completely abrogated. This result suggests that the luminescence intensity of $\mathbf{1}$ should significantly diminish in the basic mitochondrial matrix. As such, the ICP-MS data, which indicate that $\mathbf{1}$ accumulates in the mitochondria, more accurately reflect its intracellular localization compared to the speciation-dependent fluorescence microscopy data. Because the axial water ligand is susceptible to substitution, we also considered the effects of competing biologically endogenous ligands on the luminescence intensity of $\mathbf{1}$. As a brief investigation to test this hypothesis, we incubated $\mathbf{1}$ with varying concentrations of inorganic phosphate, a biologically abundant ligand, which resulted in luminescence quenching (Figure S3). Collectively, these results highlight the challenges in interpreting microscopy data obtained from this class of rhenium compounds due to their speciation-dependent luminescence properties.

Having established that $\mathbf{1}$ enters both wild-type and cisplatin-resistant ovarian cancer cells equally as effective and accumulates in the mitochondria, we initiated our efforts to investigate its in vivo anticancer activity. In our previous study, we evaluated its biodistribution and metabolism in C57Bl6 mice. ${ }^{27}$ These experiments revealed rapid renal and hepatic clearance, as reflected by the quantities of rhenium in the kidneys and liver that decreased over time. Analysis of blood and urine metabolites by HPLC-ICP-MS also revealed the presence of the intact aqua and chlorido forms of 1 after 30, 60 , and $90 \mathrm{~min}$. These data suggested that the complex has sufficient in vivo stability for use in antitumor studies.

To date, there are only two studies evaluating the in vivo anticancer activity of rhenium(I) tricarbonyl complexes. One is focused on the diselenoether compound of the formula $\left[\operatorname{Re}(\mathrm{CO})_{3}\left(2,2^{\prime}\right.\right.$-(propane-1,3-diylbis(selanediyl) $)$ diacetate $\left.)\right]^{-}$ (Re-diselenoether), ${ }^{19}$ and the other study reports a $\beta$ carboline derivative conjugated to a rhenium(I) tricarbonyl center, giving a complex with the formula $\left[\operatorname{Re}(\mathrm{CO})_{3}(1-\right.$ (quinolin-2-yl)-9H-pyrido[3,4-b]indole)(pyridine) $] \mathrm{PF}_{6}$ (Recarboline). ${ }^{22}$ Re-diselenoether showed promising in vivo anticancer activity in mice models bearing breast cancer xenografts. Treatment of mice with this drug candidate at 10 $\mathrm{mg} / \mathrm{kg}$ twice weekly for 4 weeks resulted in complete eradication of tumors. Similarly, Re-carboline inhibited tumor volumes in mice bearing lung cancer xenografts by $60 \%$ compared to vehicle mice. These promising findings encouraged us to explore the in vivo antitumor activity of 1 . We first determined the maximum tolerated dose (MTD) of 1 in $\sim 7$ week old NOD scid gamma (NSG) mice to determine an optimal dose for therapy studies. Animals were treated with 1 at 10, 20 40, 60, and $80 \mathrm{mg}$ per $\mathrm{kg}$ mouse body weight (formulation: $85 \%$ aqueous dextrose ( $5 \%$ in water), $10 \%$ DMSO, 5\% Kolliphor HS15) and observed for adverse clinical side effects over $24 \mathrm{~h}$. Pretreatment body weights and posttreatment organ weights are presented in Table S1. When the mice were treated with 10,20 , or $40 \mathrm{mg} / \mathrm{kg}$ of 1 , no adverse 

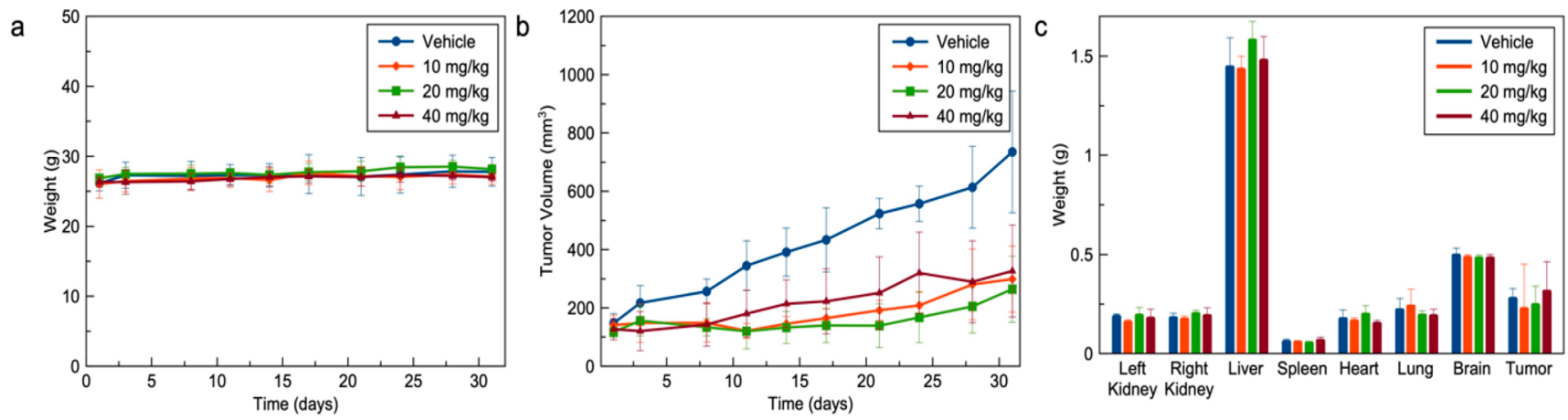

Figure 1. (a) Body weights and (b) tumor volumes of mice during treatment period and (c) weights of tissues after euthanasia of animals treated with vehicle (blue) or compound 1 at $10 \mathrm{mg} / \mathrm{kg}$ (red), $20 \mathrm{mg} / \mathrm{kg}$ (green), or $40 \mathrm{mg} / \mathrm{kg}$ (purple).

side effects were detected. By contrast, mice treated with 60 $\mathrm{mg} / \mathrm{kg}$ exhibited an initial negative reaction after which the animals recovered within $3 \mathrm{~min}$. However, their coats were not well groomed, indicating that this dosage was not well tolerated. Furthermore, injection of 1 at $80 \mathrm{mg} / \mathrm{kg}$ resulted in animal death within $30 \mathrm{~s}$ for all mice treated at this dose. Based on these dose-escalation studies, we estimate that the MTD of 1 is $40 \mathrm{mg} / \mathrm{kg}$ in NSG mice. Notably, the MTD of cisplatin in a related mouse model is $6 \mathrm{mg} / \mathrm{kg}$. ${ }^{37}$ These data suggest that $\mathbf{1}$ may be less acutely toxic than cisplatin and may be viable as a therapeutic agent due to its better tolerability.

With the MTD of $\mathbf{1}$ determined, we next investigated its antitumor properties. Ovarian cancer patient-derived xenografts $(\mathrm{PDX})^{38}$ were resected from propagation mice and implanted subcutaneously in the right flank of 20 mice. These mice were then separated into groups of five allotted to four separate treatment groups: vehicle ( $85 \%$ aqueous dextrose $(5 \%$ in water), 10\% DMSO, 5\% Kolliphor HS15) and 10, 20, and $40 \mathrm{mg} / \mathrm{kg}$ of 1 . After tumors reached over $100 \mathrm{~mm}^{3}$, mice were injected twice a week with the vehicle control or formulations of 1 via the tail vein, and their body weights and tumor volumes were monitored twice weekly for 31 days (Figures 1a,b). Notably, mice treated at all doses of $\mathbf{1}$ did not exhibit significant decreases in body weight relative to those receiving the vehicle control. This result suggests that $\mathbf{1}$ is minimally toxic over the duration of treatment. Furthermore, mice treated with 1 showed significant tumor growth inhibition relative to control animals, indicating that 1 is a potential antitumor agent that operates in vivo. Unexpectedly, no significant differences in the tumor growth were seen for the three administered doses of $\mathbf{1}$, which may suggest that a maximum biological effect is already observed at the lowest dose of $10 \mathrm{mg} / \mathrm{kg}$. All three doses resulted in approximately $60 \%$ tumor growth inhibition with respect to the vehicletreated control. For comparison, when Re-diselenoether is administered at a dose of $10 \mathrm{mg} / \mathrm{kg}$, it is able to give rise to complete tumor regression of a MDA-MB231 breast cancer orthotopic xenograft. ${ }^{19}$ However, Re-carboline is able to inhibit A549 lung cancer tumor xenograft volumes by $60 \%$ at a dosage of $5 \mathrm{mg} / \mathrm{kg}$, an effect comparable to $1 .^{22}$ The promising in vivo antitumor activities of $\mathbf{1}, \mathbf{R e}$-diselenoether, and Recarboline demonstrate how this class of compounds is effective in treating certain forms of cancer.

After the treatment period was complete, mice were euthanized, and their kidneys, liver, spleen, heart, lungs, brain, and tumor were harvested and weighed (Figure 1c) prior to fixation with $10 \%$ formalin. There were no significant differences in tissue weights between the four treatment groups, further demonstrating how 1 does not cause adverse side effects in major organs. Unexpectedly, the tumor weights among treated and untreated mice were identical within experimental error despite the fact that they were smaller in volume. In general, smaller tumors should weigh less than larger tumors. A possible explanation for this observation is that the treated tumors are denser than those from untreated mice. This explanation is consistent with histological analyses described in the following sections. Nonetheless, the growth inhibitory activity of $\mathbf{1}$ proves its efficacy as an antitumor drug candidate.

Although no detrimental side effects were observed during the treatment period, accumulation of rhenium in organs could give rise to long-term toxic side effects. To evaluate organ uptake of 1, kidneys, liver, heart, lungs, brain, and tumor were extracted from the euthanized animals in the $10 \mathrm{mg} / \mathrm{kg}$ group, digested, $^{39,40}$ and analyzed for rhenium content by ICP-MS (Table 2). These data reveal that the organs with the highest

Table 2. Rhenium Content in Tissues for Mice Treated with $10 \mathrm{mg} / \mathrm{kg} 1$ after Euthanasia ${ }^{a}$

$\begin{array}{lc}\text { tissue } & \mathrm{pg} \mathrm{Re} / \mathrm{mg} \text { tissue } \\ \text { kidneys } & 6.0 \pm 0.1 \\ \text { liver } & 10.7 \pm 0.6 \\ \text { heart } & 2.4 \pm 0.3 \\ \text { lungs } & 2.3 \pm 0.2 \\ \text { brain } & 0.84 \pm 0.04 \\ \text { tumor } & 1.0 \pm 0.3\end{array}$

${ }^{a}$ The error represents the standard error from three different mice.

concentrations of rhenium were the kidneys and liver, consistent with our previous biodistribution studies in naïve C57B16 mice. ${ }^{27}$ Moderate levels of rhenium were observed in the heart and lungs, and tissues with the lowest levels were the brain and tumor. We hypothesize that low rhenium accumulation in the brain may reflect the poor permeability of 1 through the blood-brain barrier. The lower levels of rhenium in tumors are somewhat surprising, given the tumor growth inhibitory activity of $\mathbf{1}$. This result suggests that $\mathbf{1}$ is inducing the desired antiproliferative effects in the tumor despite its relatively low uptake. Thus, improving the tumortargeting capabilities of these compounds should drastically improve their observed biological activity.

Although previous reports demonstrated the promising properties of rhenium complexes, none investigated the histopathological effects on major tissues. The levels of 

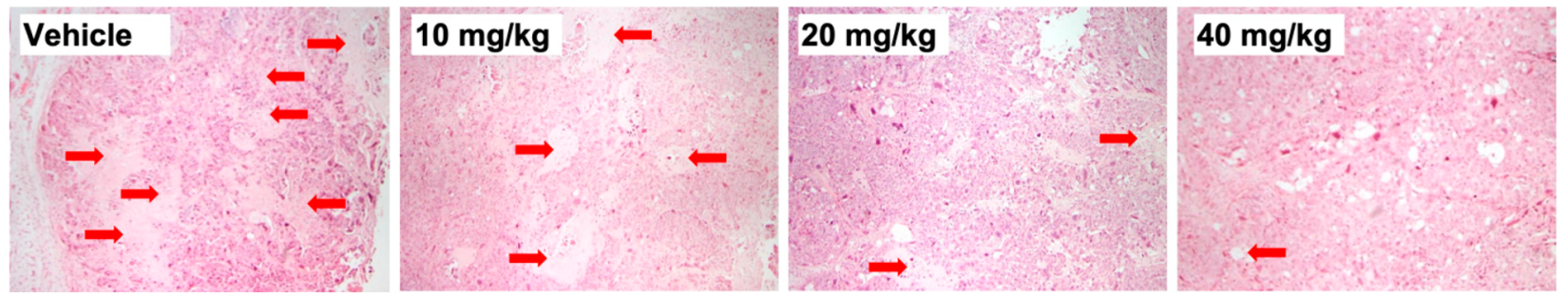

Figure 2. H\&E stained slides of tumors harvested from mice treated with vehicle or $\mathbf{1}(10,20$, and $40 \mathrm{mg} / \mathrm{kg})$. Red arrows indicate regions of necrosis.

rhenium accumulation within some of these organs may suggest that compound 1 induces long-term toxic effects. To evaluate this possibility, we explored if $\mathbf{1}$ induces tissue damage or morphological changes in these organs. The extent of tissue damage in these organs was determined by staining with hematoxylin and eosin (H\&E) and analysis by microscopy (Figures 2 and S4-S7). ${ }^{41,42}$ Examination of the liver, heart, and brain revealed no obvious tissue damage in mice treated with 1 compared to control tissues. The tumor sections, however, showed clear evidence for irreversible tissue damage, as reflected by varying degrees of necrosis in the samples analyzed. The vehicle-treated tumor exhibits $40 \%$ necrotic tissue, whereas the tumors from mice treated with 10, 20, and $40 \mathrm{mg} / \mathrm{kg}$ of 1 exhibit $25 \%, 10 \%$, and less than $5 \%$ necrotic tissue, respectively (Figure 2, Table S2). This unexpected trend of decreasing necrosis with higher doses may arise from the ability of $\mathbf{1}$ to inhibit cell growth rather than kill cells in vivo. Rapidly growing tumors lack sufficient blood supply, depriving them of nutrients, and become hypoxic, resulting in extensive necrotic cell death in the tumor core. ${ }^{43}$ Thus, we hypothesize that the tumor growth inhibition induced by $\mathbf{1}$ aided in preventing the formation of necrotic tissue. Additionally, these necrotic regions exhibit less staining by H\&E than healthy regions, illustrating less densely packed cells. Thus, the discrepancy between tumor volumes and tumor weights can be explained by the differing amounts of necrotic tissue within these specimens. Despite low rhenium content in tumors, these results confirm that $\mathbf{1}$ alters tumor morphology. Furthermore, 1 does not cause significant morphological changes in the major organs of mice, which may indicate that $\mathbf{1}$ is well tolerated.

In conclusion, we have described the cellular uptake and in vivo antitumor properties of compound 1, a previously studied rhenium(I) tricarbonyl complex shown to possess promising in vitro anticancer activity. These studies indicate that $\mathbf{1}$ accumulates preferentially in mitochondria over the nuclei and also exhibits favorable in vivo antitumor activity with limited discernible side effects. This study is only the seventh time that the in vivo antitumor activity of rhenium compound has been reported. ${ }^{17-22}$ The promising antitumor activity of 1 further supports the continued investigation of new drug candidates of rhenium. Ongoing research in our lab is focused on exploring the biological mechanisms of action of this promising class of anticancer agents.

\section{ASSOCIATED CONTENT}

\section{S Supporting Information}

The Supporting Information is available free of charge on the ACS Publications website at DOI: 10.1021/acsmedchemlett.9b00128.
Physical measurements of the rhenium complex including spectrophotometric titrations and emission spectra. Biological studies including cellular uptake, MTD studies, tumor growth inhibition, and ex vivo tissue processing (PDF)

\section{AUTHOR INFORMATION}

\section{Corresponding Author}

*E-mail: jjw275@cornell.edu.

\section{ORCID}

Chilaluck C. Konkankit: 0000-0002-3253-0132

Justin J. Wilson: 0000-0002-4086-7982

\section{Author Contributions}

The manuscript was written through contributions of all authors.

\section{Funding}

Work in our laboratory is supported by Cornell University and by the Office of the Assistant Secretary of Defense for Health Affairs through the Ovarian Cancer Research Program under award no. W81XWH-17-1-0097.

\section{Notes}

The authors declare no competing financial interest.

\section{ACKNOWLEDGMENTS}

Dr. I. Kandela is thanked for her assistance with the in vivo studies, which were supported by the Developmental Therapeutics Core at Northwestern University and the Robert H. Lurie Comprehensive Cancer Center support grant (NCI CA060553). Dr. D. N. Lisiero is thanked for assistance with histopathological analysis and general consultation. D. A. Driscoll is thanked for her assistance with ICP-MS studies. The Section of Anatomic Pathology within the Animal Health Diagnostic Center at Cornell University is thanked for their histopathology services.

\section{ABBREVIATIONS}

ICP-MS, inductively coupled plasma mass spectrometry; MTD, maximum tolerated dose; NSG, NOD scid gamma; PDX, patient-derived xenograft; H\&E, hematoxylin and eosin

\section{REFERENCES}

(1) Platinum-Based Drugs in Cancer Therapy, 1st ed.; Kelland, L. R., Farrell, N. P., Eds.; Humana Press: New York, 2000.

(2) Martin, L. P.; Hamilton, T. C.; Schilder, R. J. Platinum Resistance: The Role of DNA Repair Pathways. Clin. Cancer Res. 2008, 14, 1291-1295.

(3) Zou, T.; Lum, C. T.; Lok, C.-N.; Zhang, J.-J.; Che, C.-M. Chemical Biology of Anticancer Gold(III) and Gold(I) Complexes. Chem. Soc. Rev. 2015, 44, 8786-8801. 
(4) Cini, M.; Bradshaw, T. D.; Woodward, S. Using Titanium Complexes to Defeat Cancer: The View from the Shoulders of Titans. Chem. Soc. Rev. 2017, 46, 1040-1051.

(5) Zeng, L.; Gupta, P.; Chen, Y.; Wang, E.; Ji, L.; Chao, H.; Chen, Z.-S. The Development of Anticancer Ruthenium(II) Complexes: From Single Molecule Compounds to Nanomaterials. Chem. Soc. Rev. 2017, 46, 5771-5804.

(6) Roder, C.; Thomson, M. J. Auranofin: Repurposing an Old Drug for a Golden New Age. Drugs R\&D 2015, 15, 13-20.

(7) Alessio, E. Thirty Years of the Drug Candidate NAMI-A and the Myths in the Field of Ruthenium Anticancer Compounds: A Personal Persepective. Eur. J. Inorg. Chem. 2017, 55, 1549-1560.

(8) Trondl, R.; Heffeter, P.; Kowol, C. R.; Jakupec, M. A.; Berger, W.; Keppler, B. K. NKP-1339, the First Ruthenium-Based Anticancer Drug on the Edge to Clinical Application. Chem. Sci. 2014, 5, 29252932.

(9) Monro, S.; Colón, K. L.; Yin, H.; Roque, J., III; Konda, P.; Gujar, S.; Thummel, R. P.; Lilge, L.; Cameron, C. G.; McFarland, S. A. Transition Metal Complexes and Photodynamic Therapy from a Tumor-Centered Approach: Challenges, Opportunities, and Highlights from the Development of TLD1433. Chem. Rev. 2019, 119, $797-828$.

(10) Konkankit, C. C.; Marker, S. C.; Knopf, K. M.; Wilson, J. J. Anticancer Activity of Complexes of the Third Row Transition Metals, Rhenium, Osmium, and Iridium. Dalton Trans 2018, 47, 9934-9974.

(11) Gasser, G.; Ott, I.; Metzler-Nolte, N. Organometallic Anticancer Compounds. J. Med. Chem. 2011, 54, 3-25.

(12) Leonidova, A.; Gasser, G. Underestimated Potential of Organometallic Rhenium Complexes as Anticancer Agents. ACS Chem. Biol. 2014, 9, 2180-2193.

(13) Zhang, P.; Huang, H. Future Potential of Osmium Complexes as Anticancer Drug Candidates, Photosensitizers and OrganelleTargeted Probes. Dalton Trans 2018, 47, 14841-14854.

(14) Liu, Z.; Sadler, P. J. Organoiridium Complexes: Anticancer Agents and Catalysts. Acc. Chem. Res. 2014, 47, 1174-1185.

(15) Lee, L. C.-C.; Leung, K.-K.; Lo, K. K.-W. Recent Development of Luminescent Rhenium(I) Tricarbonyl Polypyridine Complexes as Cellular Imaging Reagents, Anticancer Drugs, and Antibacterial Agents. Dalton Trans 2017, 46, 16357-16380.

(16) Suntharalingam, K.; Awuah, S. G.; Bruno, P. M.; Johnstone, T. C.; Wang, F.; Lin, W.; Zheng, Y.-R.; Page, J. E.; Hemann, M. T.; Lippard, S. J. Necroptosis-Inducing Rhenium(V) Oxo Complexes. J. Am. Chem. Soc. 2015, 137, 2967-2974.

(17) Shtemenko, N. I.; Chifotides, H. T.; Domasevitch, K. V.; Golichenko, A. A.; Babiy, S. A.; Li, Z.; Paramonova, K. V.; Shtemenko, A. V.; Dunbar, K. R. Synthesis, X-Ray Structure, Interactions with DNA, Remarkable in Vivo Tumor Growth Suppression and Nephroprotective Activity of Cis-TetrachloroDipivalato Dirhenium(III). J. Inorg. Biochem. 2013, 129, 127-134.

(18) Shtemenko, A. V.; Collery, P.; Shtemenko, N. I.; Domasevitch, K. V.; Zabitskaya, E. D.; Golichenko, A. A. Synthesis, Characterization, in Vivo Antitumor Properties of the Cluster Rhenium Compound with GABA Ligands and Its Synergism with Cisplatin. Dalton Trans 2009, 5132-5136.

(19) Collery, P.; Mohsen, A.; Kermagoret, A.; Corre, S.; Bastian, G.; Tomas, A.; Wei, M.; Santoni, F.; Guerra, N.; Desmaële, D.; d'Angelo, J. Antitumor Activity of a Rhenium (I)-Diselenoether Complex in Experimental Models of Human Breast Cancer. Invest. New Drugs 2015, 33, 848-860.

(20) Shtemenko, N.; Collery, P.; Shtemenko, A. Dichlorotetra- $\mu$ Isobutyratodirhenium(III): Enhancement of Cisplatin Action and RBC-Stabilizing Properties. Anticancer Res. 2007, 27, 2487-2492.

(21) Shtemenko, N. I.; Collery, P.; Shtemenko, A. V. Synergistic Effect of Cisplatin and cis-Rhenium(III) Diadamantate on Tumor Growth. In Metal Ions in Biology and Medicine; John Libbey Eurotext: Paris, 2006; pp 374-378.

(22) He, L.; Pan, Z.-Y.; Qin, W.-W.; Li, Y.; Tan, C.-P.; Mao, Z.-W. Impairment of the Autophagy-Related Lysosomal Degradation
Pathway by an Anticancer Rhenium(I) Complex. Dalton Trans 2019, 48, 4398-4404.

(23) Clède, S.; Policar, C. Metal-Carbonyl Units for Vibrational and Luminescence Imaging: Towards Multimodality. Chem. - Eur. J. 2015, 21, 942-958.

(24) Hostachy, S.; Policar, C.; Delsuc, N. Re(I) Carbonyl Complexes: Multimodal Platforms for Inorganic Chemical Biology. Coord. Chem. Rev. 2017, 351, 172-188.

(25) Marker, S. C.; MacMillan, S. N.; Zipfel, W. R.; Li, Z.; Ford, P. C.; Wilson, J. J. Photoactivated in Vitro Anticancer Activity of Rhenium(I) Tricarbonyl Complexes Bearing Water-Soluble Phosphines. Inorg. Chem. 2018, 57, 1311-1331.

(26) Konkankit, C. C.; Vaughn, B. A.; MacMillan, S. N.; Boros, E.; Wilson, J. J. Combinatorial Synthesis to Identify a Potent, NecrosisInducing Rhenium Anticancer Agent. Inorg. Chem. 2019, 58, 38953909.

(27) Knopf, K. M.; Murphy, B. L.; MacMillan, S. N.; Baskin, J. M.; Barr, M. P.; Boros, E.; Wilson, J. J. In Vitro Anticancer Activity and in Vivo Biodistribution of Rhenium(I) Tricarbonyl Aqua Complexes. J. Am. Chem. Soc. 2017, 139, 14302-14314.

(28) Groessl, M.; Zava, O.; Dyson, P. J. Cellular Uptake and Subcellular Distribution of Ruthenium-Based Metallodrugs under Clinical Investigation versus Cisplatin. Metallomics 2011, 3, 591-599.

(29) Kitanovic, I.; Can, S.; Alborzinia, H.; Kitanovic, A.; Pierroz, V.; Leonidova, A.; Pinto, A.; Spingler, B.; Ferrari, S.; Molteni, R.; Steffan, A.; Metzler-Nolte, N.; Wölfl, S.; Gasser, G. A Deadly Organometallic Luminescent Probe: Anticancer Activity of a $\mathrm{Re}^{\mathrm{I}}$ Bisquinoline Complex. Chem. - Eur. J. 2014, 20, 2496-2507.

(30) Imstepf, S.; Pierroz, V.; Rubbiani, R.; Felber, M.; Fox, T.; Gasser, G.; Alberto, R. Organometallic Rhenium Complexes Divert Doxorubicin to the Mitochondria. Angew. Chem., Int. Ed. 2016, 55, $2792-2795$

(31) Imstepf, S.; Pierroz, V.; Raposinho, P.; Bauwens, M.; Felber, M.; Fox, T.; Shapiro, A. B.; Freudenberg, R.; Fernandes, C.; Gama, S.; Gasser, G.; Motthagy, F.; Santos, I. R.; Alberto, R. Nuclear Targeting with an Auger Electron Emitter Potentiates the Action of a Widely Used Antineoplastic Drug. Bioconjugate Chem. 2015, 26, 2397-2407.

(32) Gasser, G.; Neumann, S.; Ott, I.; Seitz, M.; Heumann, R.; Metzler-Nolte, N. Preparation and Biological Evaluation of DiHetero-Organometallic-Containing PNA Bioconjugates. Eur. J. Inorg. Chem. 2011, 2011, 5471-5478.

(33) Martínez, C. H. R.; Dardonville, C. Rapid Determination of Ionization Constants $\left(p \mathrm{~K}_{\mathrm{a}}\right)$ by UV Spectroscopy Using 96-Well Microtiter Plates. ACS Med. Chem. Lett. 2013, 4, 142-145.

(34) Egli, A.; Hegetschweiler, K.; Alberto, R.; Abram, U.; Schibli, R.; Hedinger, R.; Gramlich, V.; Kissner, R.; Schubiger, P. A. Hydrolysis of the Organometallic Aqua Ion fac-Triaquatricarbonylrhenium(I). Mechanism, $p \mathrm{~K}_{\mathrm{a}}$, and Formation Constants of the Polynuclear Hydrolysis Products. Organometallics 1997, 16, 1833-1840.

(35) Llopis, J.; McCaffery, J. M.; Miyawaki, A.; Farquhar, M. G.; Tsien, R. Y. Measurement of Cytosolic, Mitochondrial, and Golgi pH in Single Living Cells with Green Fluorescent Proteins. Proc. Natl. Acad. Sci. U. S. A. 1998, 95, 6803-6808.

(36) Mindell, J. A. Lysosomal Acidification Mechanisms. Annu. Rev. Physiol. 2012, 74, 69-86.

(37) Aston, W. J.; Hope, D. E.; Nowak, A. K.; Robinson, B. W.; Lake, R. A.; Lesterhuis, W. J. A Systematic Investigation of the Maximum Tolerated Dose of Cytotoxic Chemotherapy with and without Supportive Care in Mice. BMC Cancer 2017, 17, 684-693.

(38) Dong, R.; Qiang, W.; Guo, H.; Xu, X.; Kim, J. J.; Mazar, A.; Kong, B.; Wei, J.-J. Histologic and Molecular Analysis of Patient Derived Xenografts of High-Grade Serous Ovarian Carcinoma. J. Hematol. Oncol. 2016, 9, 92-102.

(39) Weekley, C. M.; Shanu, A.; Aitken, J. B.; Vogt, S.; Witting, P. K.; Harris, H. H. XAS and XFM Studies of Selenium and Copper Speciation and Distribution in the Kidneys of Selenite-Supplemented Rats. Metallomics 2014, 6, 1602-1615. 
(40) Alcock, N. W. A. Hydrogen-Peroxide Digestion System for Tissue Trace-Metal Analysis. Biol. Trace Elem. Res. 1987, 13, 363370.

(41) Azevedo Tosta, T. A.; Neves, L. A.; do Nascimento, M. Z. Segmentation Methods of H\&E-Stained Histological Images of Lymphoma: A Review. Informatics Med. Unlocked 2017, 9, 35-43.

(42) Anyz, J.; Vyslouzilova, L.; Vaculovic, T.; Tvrdonova, M.; Kanicky, V.; Haase, H.; Horak, V.; Stepankova, O.; Heger, Z.; Adam, V. Spatial Mapping of Metals in Tissue-Sections Using Combination of Mass-Spectrometry and Histology through Image Registration. Sci. Rep. 2017, 7, 1-13.

(43) Lee, S. Y.; Ju, M. K.; Jeon, H. M.; Jeong, E. K.; Lee, Y. J.; Kim, C. H.; Park, H. G.; Han, S. I.; Kang, H. S. Regulation of Tumor Progression by Programmed Necrosis. Oxid. Med. Cell. Longevity 2018, 2018, 3537471.

(44) Wang, F.-X.; Liang, J.-H.; Zhang, H.; Wang, Z.-H.; Wan, Q.; Tan, X.-P.; Ji, L.-N.; Mao, Z.-W. Mitochondria-Accumulating Rhenium(I) Tricarbonyl Complexes Induce Cell Death via Irreversible Oxidative Stress and Glutathione Metabolism Disturbance. ACS Appl. Mater. Interfaces 2019, 11, 13123-13133.

\section{NOTE ADDED IN PROOF}

Prior to acceptance of this manuscript, another study describing the in vivo anticancer activity of two rhenium(I) tricarbonyl complexes was published. ${ }^{44}$ This manuscript demonstrates the in vivo anticancer activity of two distinct rhenium compounds in mice implanted with HeLa xenografts. At an administered dose of $5 \mathrm{mg} / \mathrm{kg}$, these compounds inhibit tumor growth by approximately 50\%. Furthermore, histopathology was carried out, showing no significant pathological changes in tissue morphology. These results are broadly consistent with those reported here, providing further support for the promise of rhenium-based drug candidates. 